\title{
Durability Study of Hybrid Fiber Reinforced Concrete
}

\author{
Srinivasa Rao Naraganti* \\ Department of Civil Engineering, JB Institute of Engineering and Technology, Hyderabad, India \\ Received 30 June 2020; received in revised form 03 September 2020; accepted 17 December 2020 \\ DOI: https://doi.org/10.46604/ijeti.2021.5019
}

\begin{abstract}
Sisal has been reported as one of the promising fibers for cement composite applications. The durability of sisal fiber reinforced concrete (SFRC) and steel sisal fiber reinforced concrete (SSFRC) have not been reported. Water absorption, rapid chloride permeability, and acid attack tests are conducted on fibrous cement composites. Steel, polypropylene, and sisal fibers with a total volume of $0.50 \%, 1.00 \%, 1.25 \%$, and $1.50 \%$ were used. Sisal at a content of $1.50 \%$ in SFRC increases the water absorption by $76 \%$, but it is reduced to $30 \%$ for SSFRC with $0.2 \%$ of sisal content. SFRC and SSFRC show the increased permeability of $1.69 \%$ and $2.09 \%$ respectively. SFRC experiences the highest volume loss of $6.52 \%$. SSFRC illustrates the resistance to the mass loss and compressive strength loss. In conclusion, untreated sisal in any form is found to be not advantageous for durable fibrous concrete structures.
\end{abstract}

Keywords: polypropylene, sisal, fiber reinforced concrete, durability

\section{Introduction}

\subsection{Background}

An inherent weakness of concrete to tensile loading can be overcome by using fiber reinforced concrete (FRC). Fibers used in cement composites are broadly classified as metallic fibers (steel and carbon), synthetic fibers (polypropylene, polyester, polyvinyl alcohol, etc.), and natural fibers (kenaf, jute, sisal, coconut, etc.). FRC improved the fracture behavior of Portland cement mortar [1]. FRC was recommended not only for structures subjected to static loads but also those to impact loads due to the ability of the fibers to delay the initiation of cracks [2]. FRCs are used in the retrofitting of reinforced concrete structures [3].

Steel fibers have been dominant in improving the spectrum of properties of cement composites. Steel fiber reinforced concrete (SFRC) is capable of improving the mechanical properties of cement composites [4-5]. Some studies suggested that the SFRC could reduce the permeability [5] and water absorption [6] of concrete. Another widely accepted synthetic fiber is polypropylene (PP). They are hydrophobic, chemically inert, and available at a low cost [7]. Polypropylene fiber reinforced concrete (PFRC) improved mechanical [8] as well as durability [9] properties. However, the use of PP contributes to the greenhouse effect as it is derived from hydrocarbons. Therefore, natural fibers are considered the replacement for PP in cement composites.

Generally, natural fibers are regarded as a potential replacement for synthetic ones [10]. Among all-natural plants, sisal shows better tensile performance as it has a higher content of cellulose components [11]. Sisal fibers could be easily cultivated and used in a wide variety of applications [12]. They are one of the most commonly used vegetable fibers. They could be used

* Corresponding author. E-mail address: srininara123@gmail.com

Tel.: +91-6281776979; Fax: +91-6281776979 
as a replacement for synthetic fibers in geopolymer composites [13]. Moreover, it was observed that PP and sisal fibers, at the same content, provide a similar level of performance of residual strength [14]. Hence, sisal is considered a replacement for PP in this study.

Although Mono-FRC shows excellent performance, the hybrid fiber reinforced concrete (HyFRC) gains momentum as the synergy between the fibers results in amplified performance. The addition of steel and PP fibers results in steel polypropylene fiber reinforced concrete (SPFRC). Low cost, high life cycle properties, and sustainable characteristics can be achieved through hybridization [15]. It was observed that HyFRC enhances tensile and flexural properties as compared to Mono-FRC mixes [16]. The enhanced axial strain to the tune of $484 \%$ was reported for the hybrid glass and sisal FRC. HyFRC consisting of synthetic and natural fibers performed on par with Carbon FRC in retrofitting [17]. A hybrid combination of sisal and glass fibers were found to be effective for the retrofitting of the reinforced concrete structures [17].

\subsection{Purpose of the study}

In the present work, sisal is used as natural fiber. Though sisal fibers have high tensile properties, it has low elongation. Hence, they are blended with steel fibers to overcome the drawback of low ductility. The performance of SFRC and SSFRC are analyzed and reported. The present work focuses on the understanding performance of SFRC and SSFRC to the water absorption character, permeability character, and aggressive environment. Additionally, the performance of SFRC is compared with that of PFRC. A comparative performance analysis of SFRC vis-à-vis SFRC, PFRC, SPFRC, and SSFRC is carried out.

It was reported that steel fiber dosage of more than $3 \%$ caused a reduction in compressive strength [18]. Furthermore, a decrease in the compressive strength of SFRC was observed when the dosage of steel fiber was increased from $1 \%$ to $2 \%$ [19]. Hence, the maximum fiber dosage was limited to $2 \%$. However, the optimum steel fiber content for SPFRC was reported to be between 1-1.5\% [20]. Therefore, the author is curious to verify the engineering properties of FRC at the fiber content of $1.25 \%$; the fiber dosages of $0.50 \%, 1.00 \%, 1.25 \%$, and $1.50 \%$ by volume of concrete are considered.

\subsection{Limitations of previous research}

There is a need to encourage the development of sustainable, safe, and low-cost building construction materials to reduce the consumption of fast-depleting natural resources. Although many investigations have been conducted on the synergistic effect of hybrid fiber combinations, the limited findings have been reported on the durability of SFRC and hybrid fibers containing steel and sisal.

\section{Materials and Mix Process}

Table 1 The properties of used materials

\begin{tabular}{|c|c|c|c|}
\hline Material & Property & Test Result & Limits of the Specifications \\
\hline \multirow{4}{*}{ Cement } & Cement Specific Gravity & 3.05 & - \\
\cline { 2 - 4 } & Normal Consistency & $35.5 \%$ & - \\
\cline { 2 - 4 } & Initial Setting Time & $120 \mathrm{~min}$ & Minimum 30 min. [21] \\
\cline { 2 - 4 } & Final Setting Time & $250 \mathrm{~min}$ & Maximum 600 min. [21] \\
\cline { 2 - 4 } & Fineness $\left(\mathrm{m}^{2} / \mathrm{kg}\right)$ (Specific surface) & 290 & Minimum 225 [21] \\
\cline { 2 - 4 } & Compressive Strength (MPa) & 53.6 & Minimum 43 [21] \\
\hline \multirow{3}{*}{ Coarse Aggregate } & Specific Gravity & 2.67 & - \\
\cline { 2 - 4 } & Water Absorption & $1.07 \%$ & $2.00 \%[22]$ \\
\hline \multirow{3}{*}{ Fine Aggregate } & Specific Gravity & 2.55 & - \\
\cline { 2 - 4 } & Water Absorption & $1.03 \%$ & $2.50 \%[23]$ \\
\cline { 2 - 4 } & Sieve Analysis & Zone I & - \\
\cline { 2 - 4 } & Fineness Modulus & 2.76 & - \\
\hline Superplasticizer & Solid Content & $30.77 \%$ & - \\
\hline
\end{tabular}


Ordinary Portland cement of grade 43 conforming to the code IS:8112 (2013) [21] was used. As per Indian standard, the grade refers to the minimum compressive strength of cement in MPa after 28 days of curing. The locally available crushed stone confirmed to IS:383 (2002) [22] was used as coarse aggregate with a maximum size of 20 mm. Natural river sand confirmed to IS:383 (2002) [22] was used as a fine aggregate. A detailed sieve analysis revealed that the fine aggregate belonged to zone II based on the specifications outlined in IS:383 (2002) [22]. Naphthalene sulfonate based on superplasticizer (SP) confirmed to IS:9103 (2004) [23] was used for all mix proportions. SP dosage of 1\% by the weight of cement was used throughout the experimental work to maintain the workability. Table 1 shows the properties of various materials used to make the concrete.

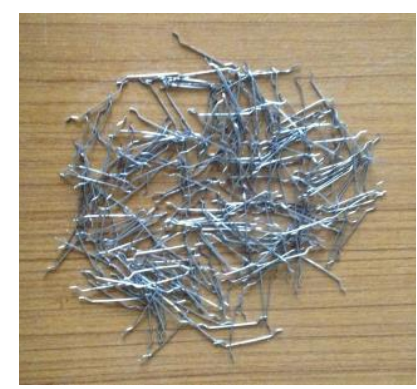

(a) Steel fibres

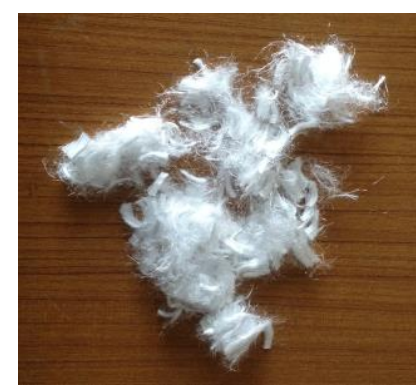

(b) PP fibres

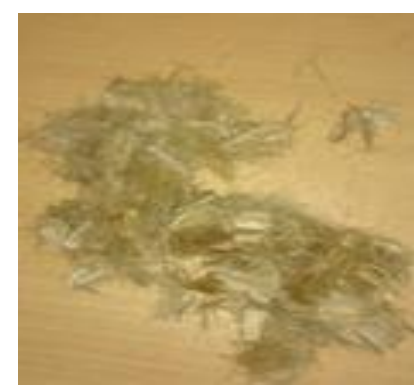

(c) Sisal fibres

Fig. 1 Fibers used

Hooked-end steel fibers of $30 \mathrm{~mm}$ length and $0.5 \mathrm{~mm}$ thickness, the monofilament PP fibers of $12 \mathrm{~mm}$ length, and manually extracted locally available sisal fibers of $12 \mathrm{~mm}$ length were used. Fig. 1 demonstrates the images of steel, PP, and sisal fibers used in the research. The basic properties of them are presented in Table 2 . The fiber content of $0.50 \%, 1.00 \%$, $1.25 \%$, and $1.50 \%$ by the volume of concrete were used. Concrete mix design for M30 is done based on guidelines given in IS:10262 (2009) [24]. The quantities of different ingredients per $1 \mathrm{~m}^{3}$ of the control mix are depicted in Table 3. Furthermore, the mix proportions used in this work are presented in Table 4. The mixing process adopted for FRC is depicted in Fig. 2.

Table 2 Properties of fibers used

\begin{tabular}{|c|c|c|c|}
\hline Name of Property & Steel & PP & Sisal \\
\hline Length (mm) & 30 & 12 & 12 \\
\hline Thickness (mm) & 0.5 & 0.022 & 0.09 \\
\hline Aspect Ratio & 60 & 545 & 133 \\
\hline Specific Gravity & 7.8 & 0.9 & 1.4 \\
\hline Modulus of Elasticity (GPa) & 200 & 4 & 16 \\
\hline Tensile Strength (MPa) & 1050 & 400 & 560 \\
\hline
\end{tabular}

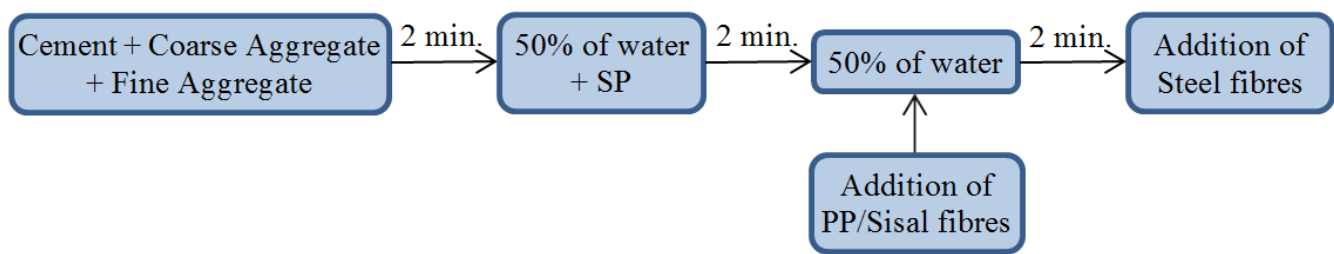

Fig. 2 Mix process

Table 3 The details of the control mix

\begin{tabular}{|c|c|c|c|c|}
\hline Cement $(\mathrm{kg})$ & Fine aggregate $(\mathrm{kg})$ & Coarse aggregate $(\mathrm{kg})$ & W/C & SP $(\%)$ \\
\hline 354.88 & 617.83 & 1183.35 & 0.50 & 1.0 \\
\hline
\end{tabular}

Table 4 Mix proportions

\begin{tabular}{|c|c|c|c|c|c|c|}
\hline Mix & $\begin{array}{c}\text { Total fiber vol. } \\
(\%)\end{array}$ & $\begin{array}{c}\text { Steel vol. } \\
(\%)\end{array}$ & $\begin{array}{c}\text { PP } \\
\text { vol. }(\%)\end{array}$ & $\begin{array}{c}\text { Sisal vol. } \\
(\%)\end{array}$ & Proportions of Steel + PP & Proportions of Steel + Sisal \\
\hline PCC & - & - & - & - & - & - \\
\hline S050 & 0.50 & 0.50 & - & - & - & - \\
\hline S100 & 1.00 & 1.00 & - & - & - & - \\
\hline
\end{tabular}


Table 4 Mix proportions (continued)

\begin{tabular}{|c|c|c|c|c|c|c|}
\hline Mix & $\begin{array}{c}\text { Total fiber vol. } \\
(\%)\end{array}$ & $\begin{array}{c}\text { Steel vol. } \\
(\%)\end{array}$ & $\begin{array}{c}\text { PP } \\
\text { vol. }(\%)\end{array}$ & $\begin{array}{l}\text { Sisal vol. } \\
(\%)\end{array}$ & Proportions of Steel + PP & Proportions of Steel + Sisal \\
\hline $\mathrm{S} 125$ & 1.25 & 1.25 & - & - & - & - \\
\hline $\mathrm{S} 150$ & 1.50 & 1.50 & - & - & - & - \\
\hline $\mathrm{P} 050$ & 0.50 & - & 0.50 & - & - & - \\
\hline $\mathrm{P} 100$ & 1.00 & - & 1.00 & - & - & - \\
\hline $\mathrm{P} 125$ & 1.25 & - & 1.25 & - & - & - \\
\hline $\mathrm{P} 150$ & 1.50 & - & 1.50 & - & - & - \\
\hline $\mathrm{Si050}$ & 0.50 & - & - & 0.50 & - & - \\
\hline Si100 & 1.00 & - & - & 1.00 & - & - \\
\hline Si125 & 1.25 & - & - & 1.25 & - & - \\
\hline Si150 & 1.50 & - & - & 1.50 & - & - \\
\hline SP050 & 0.50 & - & - & - & $0.4+0.1$ & - \\
\hline SP100 & 1.00 & - & - & - & $0.8+0.2$ & - \\
\hline SP125 & 1.25 & - & - & - & $1.0+0.25$ & - \\
\hline SP150 & 1.50 & - & - & - & $1.35+0.15$ & - \\
\hline SSi050 & 0.50 & - & - & - & - & $0.4+0.1$ \\
\hline SSi100 & 1.00 & - & - & - & - & $0.8+0.2$ \\
\hline SSi125 & 1.25 & - & - & - & - & $1.125+0.125$ \\
\hline SSi150 & 1.50 & - & - & - & - & $1.35+0.15$ \\
\hline
\end{tabular}

\section{Methodology}

\subsection{Water absorption}

The water absorption test was conducted on cylindrical specimens of size $100 \mathrm{~mm}$ x $50 \mathrm{~mm}$ after 28 days of curing as per ASTM: C642 (1997) [25]. Three test specimens were cast for each mix and tested for water absorption. After the curing period, these specimens were oven-dried for 24 hours at the temperature of $1100^{\circ} \mathrm{C}$, and the oven-dry weight of specimens was measured.

The test specimens were immersed in water and measured the weight of the saturated surface dry specimens at an interval of 12 hours. This procedure was repeated for not less than 48 hours until the two successive readings were the same to ensure that the concrete specimens were absorbing more water. The percentage of water absorption was calculated from the weight of the oven-dry specimen and saturated surface dry specimen. Three specimens were used for each mix, and average values are reported.

\subsection{Rapid chloride permeability test}

Rapid chloride permeability test (RCPT) gives a rapid indication of the resistance of concrete to chloride ion penetration. In other words, the test provides an insight into the electrical conductance of concrete samples. It is widely accepted that the durability of concrete is significantly affected by the property of the concrete to resist chloride ion penetration. The standard test method for the electrical indication of concretes ability to resist the ingression of chloride ion was conducted on the specimens as per ASTMC1202 (2007) [26].

RCPT was conducted on cylindrical specimens after 28 days of curing. The specimens of size $100 \mathrm{~mm} \times 50 \mathrm{~mm}$ were used to conduct this test. Three specimens were tested for each mix, and the average value was reported. RCPT set-up consists of a two-component cell assembly. This assembly was checked for air and watertight before starting the test. The anode compartment was filled with $0.3 \mathrm{NaOH}$ solution, and the cathode compartment was filled with a $3 \% \mathrm{NaCl}$ solution. A potential difference of $60 \mathrm{~V}$ from DC power source was applied between cathode and anode for the concrete specimen. The current was monitored up to 6 hours at an interval of 30 minutes. Samples were removed from the cell after 6 hours, and the average permeability of the specimen in terms of Coulombs was calculated. 


\subsection{Acid attack test}

The resistance against the external acid attack is evaluated for all concrete mixes as per ASTMC267 (2001) [27]. The cubes of size $150 \times 150 \times 150 \mathrm{~mm}$ were prepared and cured them for 28 days in water. The concrete specimens were then taken out of the tank and cleaned with a dry cloth; the initial weight was taken. The specimens were immersed in a $3 \%$ sulfuric acid solution for 28 days. The weight, dimensions, and compressive strength of the specimen were recorded at the age of 28 days of immersion in an acid tank. Properties, such as a change in volume, mass loss, and change in compressive strength were evaluated. Three specimens were used for each mix, and average values were reported.

\section{Results and Discussion}

\subsection{Water absorption}

Water absorption test results of various mixes are shown in Fig. 3. The mix SP150 absorbs less water as compared to the control mix, and the mix Si150 absorbs a maximum water content of 3.34\%. The increase in fiber content of SFRC results in a reduction in the water absorption considerably. For example, the fiber content of $0.50 \%$ of steel reduces the water absorption by $16.8 \%$ as compared to the control mix. However, this reduction in water absorption is increased by $39.7 \%$ as compared to the control mix when the fiber content is increased to $1.50 \%$. The increased content of steel fibers results in a reduction of water absorption of SFRC mainly due to the less porous and well-compacted structure between steel fibers and cement matrix. The well-compacted interfacial zone has fewer pores and thereby, the SFRC shows lower water absorption with an increase in fiber content. Hence, the water absorption capacity of SFRC decreases with an increase in fiber content. These findings are in complete agreement with some reported findings [6].

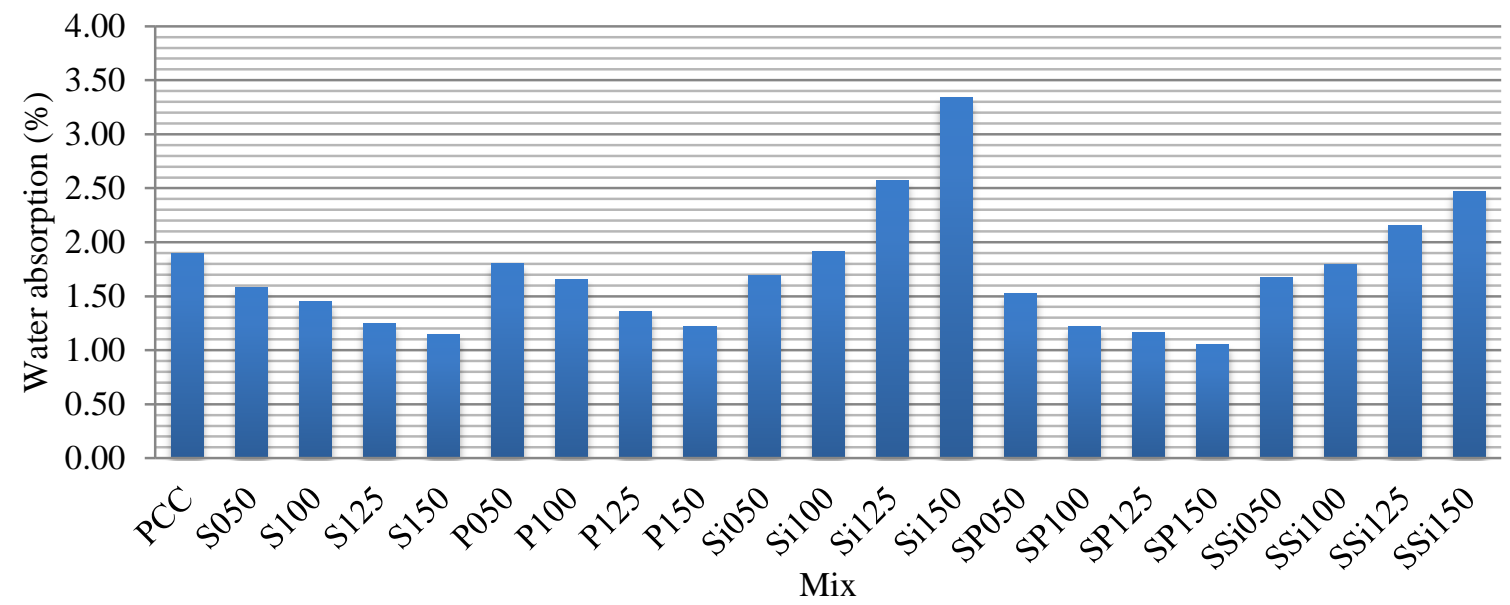

Fig. 3 Water absorption of various mixes

An increase in resistance to water absorption is observed with an increase in the content of PP. Water absorption in the range of $1.22-1.80 \%$ is observed for PFRC. The less permeable structure of PFRC is attributed to a decrease in water absorption. The presence of sisal showed an adverse effect on the water absorption of FRC for the fiber dosages of $1.25 \%$ and $1.50 \%$. However, SFRC demonstrates the performance close to PFRC at the volume fractions $0.50 \%$ and $1.00 \%$. Increasing the content of sisal fibers amplifies the water absorption capacity of the cement composites at the content of $1.25 \%$ and $1.50 \%$. The water absorption was found to be in the range of $1.69 \%$ to $3.34 \%$ for SFRC. The hydrophilic nature of sisal causes it to absorb more water. Additionally, the weak interfacial transition zone between the matrix and the sisal creates more pores. The water absorbed by the SFRC is replaced with the pores in the cement composites. These two factors result in higher water absorption of SFRC at the higher content. Therefore, the use of SFRC has a detrimental effect if the structure gets in contact with water. However, it requires further research to evaluate the performance of treated sisal fibers in durable cement composites. 
SPFRC continues to dominate the performance of resisting the water absorption capacity of FRC. The water absorption for HyFRC ranged from $1.52 \%$ to $1.05 \%$ with an increase in total volume fractions. Mix SP150 showed the lowest water absorption of $1.05 \%$, which is $44.4 \%$ less than that of the control mix. The improved performance of SPFRC is the result of the availability of different porous structures between the fiber and cement matrix, and varying lengths of pores due to different lengths of the fibers. In addition, the discontinuity of the pores makes it difficult for the water to penetrate to the core of the specimen [5].

SSFRC showed the water absorption of $1.67 \%$ and $1.79 \%$ for the volume content of $0.50 \%$ and $1.00 \%$ respectively. Although these mixes illustrates the water absorption less than that of the control mix, SSFRC with the total volume content of $1.25 \%$ and $1.50 \%$ surpasses the water absorption of the control mix. The water absorption of SSFRC reaches as high as $2.47 \%$ at the volume content of $1.50 \%$. This is mainly because of the availability of more number of sisal fibers at the higher fiber content. It is noticed that both the hybrid combinations (SPFRC and SSFRC) showed similar water absorption characteristics at a low volume of sisal $(0.5 \%)$ due to the high content of steel fibers. Nevertheless, the gap in their performance widens with an increase in total volume fractions, owing to the demerits of sisal. Though the synergy between steel and sisal is reported in mechanical properties of SSFRC, similar synergy is not evident for water absorption capacity of SSFRC [2].

\subsection{Rapid chloride permeability test}

The graphical representation of the test results for various mix proportions is depicted in Fig. 4. It is obvious that an increase in the fiber content improves the resistance to penetration of chloride ions into the core of SFRC and HyFRC. On the contrary, the presence of the fibers showed a deleterious effect for PFRC and SFRC. RCPT ratings as given by ASTMC1202 (2007) [26] are presented in Table 5.

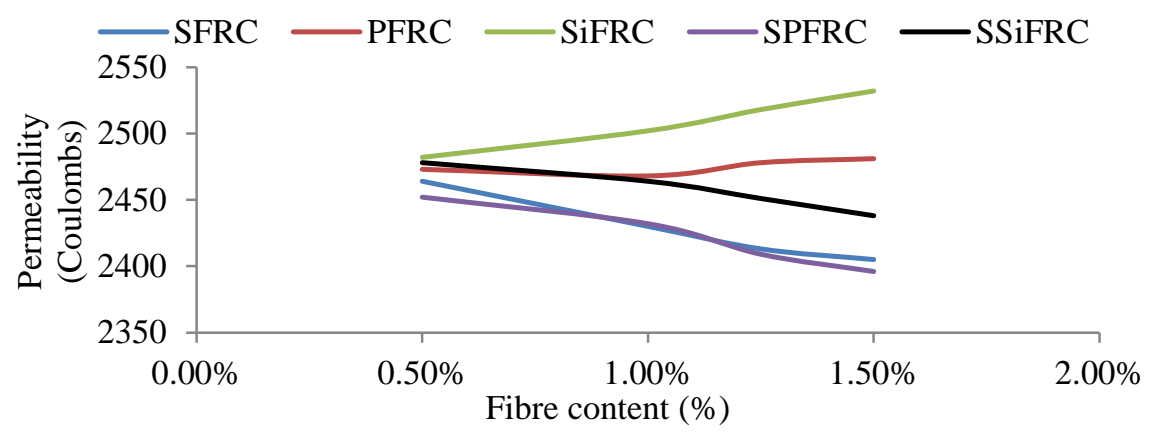

Fig. 4 Average permeability of various mixes

An increase in fiber content of steel illustrates more resistance to the penetration of chloride ions as represented in Fig. 4. The lowest permeability of 2396 Coulombs is noticed for the mix SP150. This lowest permeability is attributed to the dense microstructure of SFRC [5]. The permeability for SFRC was found to be in the range of 2464to2405 Coulombs.

Table 5 RCPT Ratings [27]

\begin{tabular}{|c|c|c|}
\hline S. No. & The charge passed (Coulombs) & Chloride ion permeability \\
\hline 1 & $>4000$ & High \\
\hline 2 & $2000-4000$ & Moderate \\
\hline 3 & $1000-2000$ & Low \\
\hline 4 & $100-1000$ & Very low \\
\hline 5 & $<100$ & Negligible \\
\hline
\end{tabular}

All PFRC mix proportions showed less permeability as compared to the non-fibrous mix. Nonetheless , the present findings are not in line with some published reports [28]. SFRC demonstrates an increase in permeability with an increase in fiber content. The permeability in the range of 2482 to 2532 Coulombs is observed for SFRC. The increased permeability of SFRC with an increase in volume content is mainly attributed to the porous structure of the fiber itself and relatively weak interface between the fiber and cement matrix [12]. 
An increase in the content of sisal in SSFRC resultes in lower permeability. The average permeability of SSFRC decreases steadily from 2478 to 2438 Coulombs with an increase in volume content from $0.50 \%$ to $1.50 \%$. The relatively lower content of sisal and synergy between the steel and sisal has contributed to less permeability of SSFRC with an increase in fiber content. Although SPFRC and SSFRC show the distinctive performance at the volume fraction of $0.50 \%$ and $1.50 \%$, they showed a similar performance at the volume content of $1.00 \%$ and $1.25 \%$. In contrast, PFRC, SFRC, and SSFRC present similar performance at a low volume fraction of $0.50 \%$. These three FRC mixed proportions perform differently with an increase in volume content beyond $0.50 \%$. It can be observed that PFRC and SSFRC (with the total sisal content of $10 \%$ to $20 \%$ ) demonstrates similar performance until a fiber content of $1.00 \%$. The presence of sisal alone causes more permeability in fibrous composites, and it is more so at higher volume content. However, SSFRC results in lower permeability due to the presence of higher content of steel fibers. Therefore, the use of sisal fibers in cement composites is not advantageous.

\subsection{Acid attack test}

The integrity of the specimen after subjected to the aggressive environment is measured in terms of the change in volume of the specimen. The experimental investigation reveals that the non-fibrous mix reduces its volume by $4.6 \%$. Observed from Fig. 5, the lowest change in volume is recorded for the mix SP150, and the most vulnerable mix to the aggressive environment is Si150. The image of a specimen under compressive loading and subjected to an acid attack is depicted in Fig. 6.

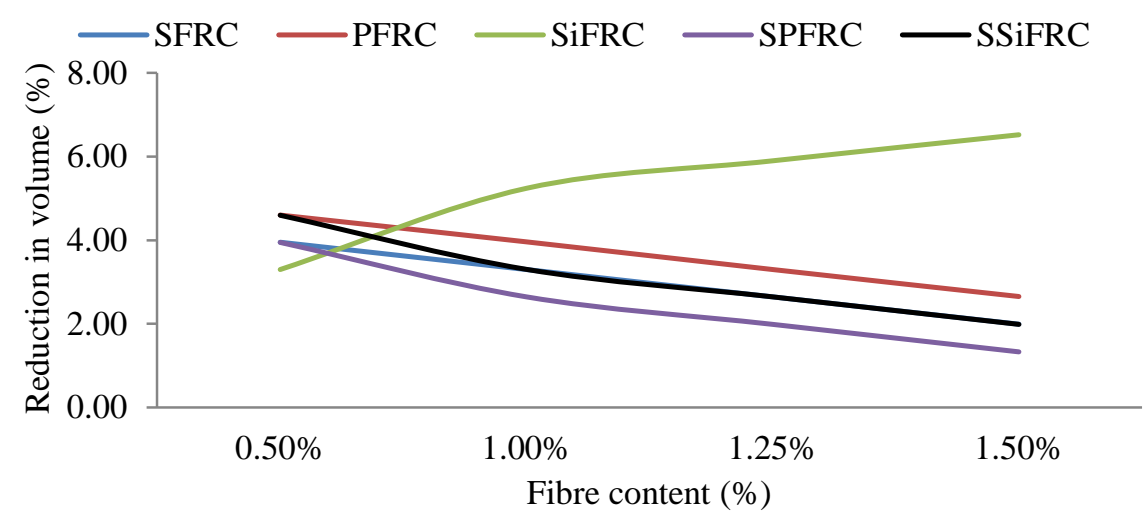

Fig. 5 Change in volume of various mixes

The fiber dosages of $0.50 \%, 1.00 \%, 1.25 \%$, and $1.50 \%$ of steel resulted the reduction in volume of $3.95 \%, 3.30 \%, 2.64 \%$, and $1.99 \%$ respectively. Although steel fibers are susceptible to an aggressive acidic environment, an increase in volume content of steel improves the resistance to the volume change of SFRC. The well-compacted and less porous interface might have restricted the ingression of acid into the center of the specimen and thereby protecting the loss of steel fibers lying deep inside the specimen.

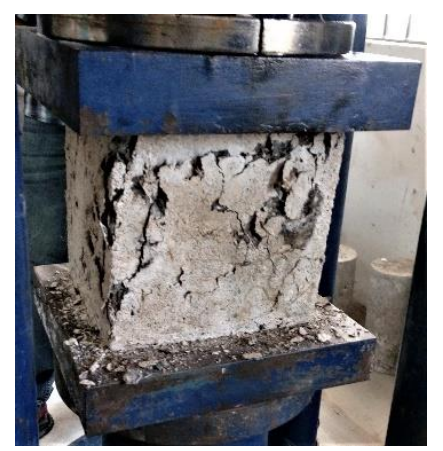

Fig. 6 A close-view of the specimen after acid attack

Furthermore, an increase in the content of PP also improve the resistance to change in the volume of PFRC after subjected to an aggressive acidic environment. However, at the low volume fraction of PP (0.50\%), PFRC doesn't show any improvement in resisting the volume change, and the response is the same as that of a non-fibrous mix. Nonetheless, the 
resistance to volume change is observed with an increase in the content of PP fibers. A relatively weak interfacial zone at the out surface of the specimen allows the ingression of corrosive substances into the specimen. Nevertheless, the discontinuous paths which are developed due to the presence of PP fibers might have restricted the effect of aggressive environment deep inside the specimen.

SFRC illustrates different performance as compared to SFRC and PFRC in resisting volume change under an aggressive environment. An increase in the content of sisal rise the loss of volume of SFRC. However, at a low volume fraction of $0.50 \%$, SFRC performs better than PCC. In total, a reduction in the volume of SFRC is found to be in the range of 3.3to $6.5 \%$.

SPFRC continues to excel in retaining the volume of concrete in the acidic environment. The lowest volume reduction of $1.3 \%$ is observed for the mix SP150. Moreover, all mix proportions of SPFRC shows superior performance for all total fiber content. On the other hand, SSFRC presents the performance similar to SFRC for all fiber dosages except for $0.50 \%$. This may be due to the small content of sisal in the SSFRC specimens. However, the presence of more steel fibers brings the performance at par with that of SFRC. It is evident from the results that the addition of sisal fibers makes the specimen susceptible to an aggressive environment. SFRC loses more volume as compared to SSFRC at the same volume content. Therefore, the presence of sisal alone in concrete composites is detrimental in retaining the volume of the concrete.

Fig. 7 depicts the performance of all mix proportions in resisting mass loss in an aggressive environment. Almost all mix proportions shows the same level of performance at a low volume because the fiber effect is negligible when content is $0.50 \%$. However, more gap in performance is observed as the volume content is increased. The volume change reflects a similar change in mass. The rate of volume change does not proportionately influence the change in mass.

SFRC shows a mass loss in the range of $1.57 \%$ to $1.01 \%$. An increase in fiber content of SFRC reduces the mass loss. The dense interfacial zone and availability of more number of steel at higher fiber content are the reasons for reduced mass loss of SFRC. Nonethless, nearly the same mass loss of SFRC and control mix is observed at the volume content of $0.50 \%$. PFRC also shows the performance similar to that of SFRC at all fiber dosages. The lowest mass loss of $1.14 \%$ is observed at a volume content of $1.50 \%$. The availability of more number of PP fibers at higher fiber content is the primary reason for PFRC to retain its mass in an aggressive environment. The vulnerability of sisal in cement composites is observed in an aggressive environment as well. SFRC loses as high as $2.69 \%$ mass at the volume content of $1.50 \%$. The biodegradability of sisal in an acidic environment is the primary reason for high mass loss.

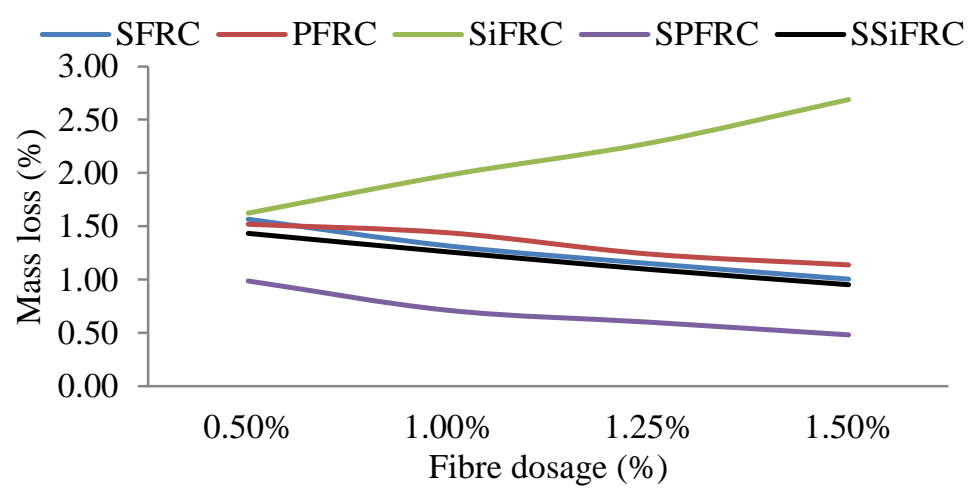

Fig. 7 Mass loss of various mixes

It is evident from the test results that the HyFRC outperforms Mono-FRC at all dosages. SPFRC shows superior performance among all mix proportions including SSFRC in retaining the mass. An increase in total volume fractions improves the resistance to mass loss, and minimum mass loss of $0.48 \%$ is observed for the mix SP150. This superior performance of SPFRC is mainly attributed to the dense interfacial zone between the steel and cement matrix, and synergy between the fibers. However, SSFRC reduces the mass loss considerably. The week interfacial bonding between the sisal fibers and cement matrix, and biodegradability of sisal results in higher mass loss of SSFRC as compared to SPFRC. Although 
SPFRC shows less mass loss even at the volume content of $0.50 \%$, all other mix proportions present similar performance at the volume content of $0.50 \%$. The mix proportions of PFRC, SFRC, and SSFRC demonstrates a more or less similar response at different dosages. However, the poor performance of SFRC in resisting mass loss continues with an increase in fiber content.

The compressive strength of various mix proportions before and after acid attack test at 28 days is presented in Table 6 . Additionally, a change in compressive strength is reported.

Table 6 Compressive strength loss of mixes after 28 days

\begin{tabular}{|c|c|c|c|}
\hline Mix & $\begin{array}{c}\text { Compressive strength } \\
\text { before acid attack }\left(\mathrm{N} / \mathrm{mm}^{2}\right)\end{array}$ & $\begin{array}{c}\text { Compressive strength after } \\
\text { the acid attack }\left(\mathrm{N} / \mathrm{mm}^{2}\right)\end{array}$ & $\begin{array}{c}\text { Change in Compressive } \\
\text { strength }(\%)\end{array}$ \\
\hline PCC & 40.62 & 31.56 & -22.3 \\
\hline S050 & 42.13 & 35.12 & -16.6 \\
\hline S100 & 43.71 & 38.32 & -12.3 \\
\hline S125 & 44.35 & 39.68 & -10.5 \\
\hline S150 & 45.07 & 40.89 & -9.3 \\
\hline P050 & 40.78 & 33.04 & -19.0 \\
\hline P100 & 41.87 & 35.31 & -15.7 \\
\hline P125 & 42.21 & 36.82 & -12.8 \\
\hline P150 & 42.62 & 38.19 & -10.4 \\
\hline Si050 & 40.76 & 32.61 & -20.0 \\
\hline Si100 & 41.68 & 33.86 & -18.8 \\
\hline Si125 & 42.49 & 34.91 & -17.8 \\
\hline Si150 & 42.96 & 35.68 & -16.9 \\
\hline SP050 & 42.32 & 38.42 & -9.2 \\
\hline SP100 & 43.91 & 41.21 & -6.1 \\
\hline SP125 & 45.12 & 42.90 & -4.9 \\
\hline SP150 & 45.08 & 43.29 & -4.0 \\
\hline SSi050 & 42.37 & 35.81 & -15.5 \\
\hline SSi100 & 44.06 & 39.41 & -10.6 \\
\hline SSi125 & 45.16 & 41.43 & -8.3 \\
\hline SSi150 & 44.86 & 42.28 & -5.8 \\
\hline
\end{tabular}

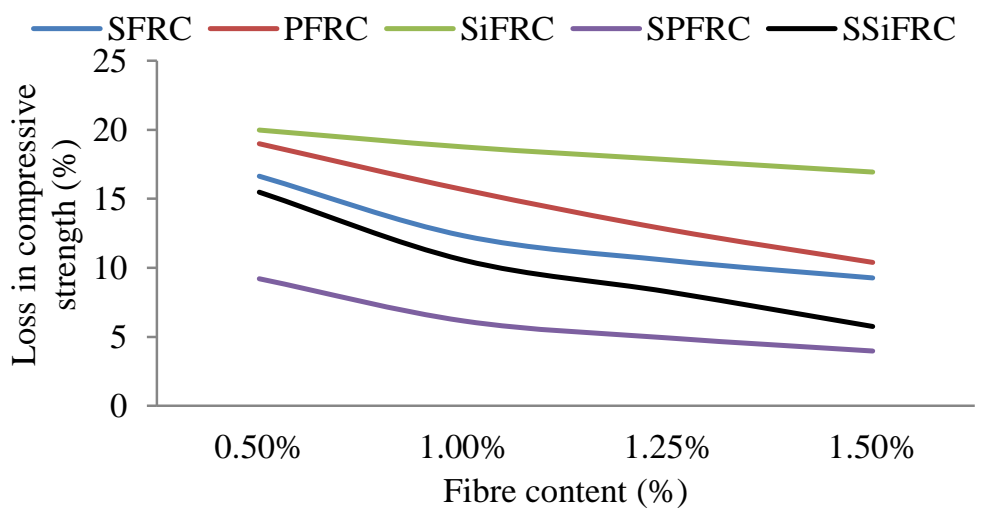

Fig. 8 Compressive strength loss of mixes at 28 days

Fig. 8 depicts the comparative performance of all mix proportions in resisting compressive strength. It can be observed that even at low volume fraction, each mix proportion shows the performance at different levels. The lowest and highest resistance to the loss in compressive strength is observed for SPFRC and SFRC respectively. Although PFRC and SFRC illustrate close performance at low volume fractions, SFRC continues to be vulnerable to compressive strength loss in the acidic environment at higher fiber dosages.

\section{Conclusions}

Though SFRC and PFRC reduced the water absorption, SFRC exhibited higher water absorption capacity with an increase in fiber content. At a fiber content of $1.50 \%$, the water absorption increased by $76 \%$ as compared to the control mix. The water absorption capacity of SSFRC increased by about $30 \%$ for the total fiber content of $1.50 \%$, where the sisal is only 
$0.2 \%$, which is negligible. The permeability of SFRC increased by $1.69 \%$ at fiber content of $1.50 \%$. Higher content of sisal resulted in higher permeability. In contrast, SFRC, PFRC, and SPFRC showed less permeability. SSFRC presented higher permeability with an increase in sisal content. An increase of $2.09 \%$ in permeability was noticed at total sisal content of $0.2 \%$.

An increase in fiber content resulted in less loss in volume for SFRC, PFRC, and SPFRC. Highest volume loss of $6.52 \%$ was observed for SFRC at a total volume content of $1.50 \%$. An increase in sisal content resulted in higher volume loss for SFRC. SFRC retained the volume with an increase in fiber content. A volume loss of $1.99 \%$ was observed at total sisal content of $0.2 \%$. SFRC was susceptible to mass loss. A mass loss of $2.69 \%$ was noticed for SFRC at a fiber content of $1.50 \%$. However, SFRC, PFRC, and SPFRC are found to be effective in retaining mass of FRC. An increase in sisal content in SSFRC did not show an adverse effect on mass loss as the total fiber content was only $0.2 \%$. SFRC illustrated only a compressive strength loss of $16.94 \%$ as compared to $22.3 \%$ of control mix even at a fiber dosage of $1.50 \%$. SFRC, PFRC, and SPFRC retained compressive strength better as compared to SFRC. SSFRC lost only 5.75\% of compressive strength at a total volume fraction of $1.50 \%$, where the sisal was only $0.2 \%$, which is negligible.

It is safe to conclude that sisal in concrete as mono-FRC or HyFRC at any fiber content turned out to be not advantageous. Hence, the use of untreated sisal is not recommended for durable cement composites in any way and at any content. The treatment of sisal fibers can protect them from biodegradability and help contribute to enhanced engineering properties of FRC. This research work can be extended to evaluate engineering properties of SFRC and SSFRC using chemically treated sisal fibers.

\section{Conflicts of Interest}

The authors declare no conflict of interest.

\section{References}

[1] E. Campello, M. V. Pereira, and F. Darwish, "The Effect of Short Metallic and Polymeric Fiber on the Fracture Behavior of Cement Mortar,” Procedia Materials Science, vol. 3, pp. 1914-1921, 2014.

[2] S. R. Naraganti, R. M. R. Pannem, and J. Putta, "Impact Resistance of Hybrid Fibre Reinforced Concrete Containing Sisal Fibres,” Ain Shams Engineering Journal, vol. 10, no. 2, pp. 297-305, June 2019.

[3] R. V. Upadhyaya and T. G. Suntharavadivel, "Optimization of Flyash and Metakaolin Content in Mineral Based CFRP Retrofit for Improved Sustainability,” International Journal of Engineering and Technology Innovation, vol. 9, no. 3, pp. 171-181, May 2019.

[4] G. Giaccio, M. E. Bossio, M. C. Torrijos, and R. Zerbino, "Contribution of Fiber Reinforcement in Concrete Affected by Alkalisilica Reaction,” Cement and Concrete Research, vol. 67, pp. 310-317, January 2015.

[5] S. Abbas, A. M. Soliman, and M. L. Nehdi, "Exploring Mechanical and Durability Properties of Ultra-High Performance Concrete Incorporating Various Steel Fiber Lengths and Dosages," Construction and Building Materials, vol. 75, pp. 429-441, January 2015.

[6] K. Behfarnia and A. Behravan, "Application of High Performance Polypropylene Fibers in Concrete Lining of Water Tunnels," Materials and Design, vol. 55, pp. 274-279, March 2014.

[7] H. A. Maddah, "Polypropylene as a Promising Plastic: A Review," American Journal of Polymer Science, vol. 6, no. 1, pp. 1-11, 2016.

[8] M. Saidani, D. Saraireh, and M. Gerges, "Behaviour of Different Types of Fibre Reinforced Concrete without Admixture," Engineering Structures, vol. 113, pp. 328-334, April 2016.

[9] T. A. Söylev and T. Zturan, "Durability, Physical and Mechanical Properties of Fiber-reinforced Concretes at Low-volume Fraction," Construction and Building Materials, vol. 73, pp. 67-75, December 2014.

[10] L. Yan and N. Chouw, "Natural FRP Confined Fibre Reinforced Concrete under Pure Axial Compression: A Comparison with Glass/Carbon FRP," Thin-Walled Structures, vol. 82, pp. 159-169, September 2014.

[11] M. P. Staiger and N. Tucker, 8 - Natural-fibre Composites in Structural Applications, 1st ed. Cambridge: Woodhead Publishing, 2008. 
[12] K. Senthilkumar, N. Saba, N. Rajini, M. Chandrasekar, M. Jawaid, S. Siengchin, et al., "Mechanical Properties Evaluation of Sisal Fibre Reinforced Polymer Composites: A Review," Construction and Building Materials, vol. 174, pp. 713-729, June 2018.

[13] A. Wongsa, R. Kunthawatwong, S. Naenudon, V. Sata, and P. Chindaprasirt, "Natural Fiber Reinforced High Calcium Fly Ash Geopolymer Mortar," Construction and Building Materials, vol. 241, article no. 118143, April 2020.

[14] R. S. Castoldi, L. M. S. Souza, and F. A. Silva, "Comparative Study on the Mechanical Behavior and Durability of Polypropylene and Sisal Fiber Reinforced Concretes," Construction and Building Materials, vol. 211, pp. 617-628, June 2019.

[15] H. S. Kim and Y. S. Shin, "Flexural Behavior of Reinforced Concrete (RC) Beams Retrofitted with Hybrid Fiber Reinforced Polymers (FRPs) under Sustaining Loads,” Composite Structures, vol. 93, no. 2, pp. 802-811, January 2011.

[16] C. B. C. Bello, I. Boem, A. Cecchi, N. Gattesco, and D. V. Oliveira, "Experimental Tests for the Characterization of Sisal Fiber Reinforced Cementitious Matrix for Strengthening Masonry Structures," Construction and Building Materials, vol. 219, pp. 44-55, September 2019.

[17] A. Padanattil, J. Karingamanna, and K. M. Mini, "Novel Hybrid Composites based on Glass and Sisal Fiber for Retrofitting of Reinforced Concrete Structures," Construction and Building Materials, vol. 133, pp. 146-153, February 2017.

[18] M. S. Meddah and M. Bencheikh, "Properties of Concrete Reinforced with Different Kinds of Industrial Waste Fibre Materials," Construction and Building Materials, vol. 23, no. 10, pp. 3196-3205, October 2009.

[19] R. S. Olivito and F. A. Zuccarello, “An Experimental Study on the Tensile Strength of Steel Fiber Reinforced Concrete," Composites: Part B, vol. 41, no. 3, pp. 246-255, April 2010.

[20] H. T. Wang and L. C. Wang, "Experimental Study on Static and Dynamic Mechanical Properties of Steel Fiber Reinforced Lightweight Aggregate Concrete," Construction and Building Materials, vol. 38, pp. 1146-1151, January 2013.

[21] Indian Standard Ordinary Portland Cement, 43 Grade-Specification, 2nd ed. New Delhi: Bureau of Indian Standards, 2013.

[22] Indian Standard, Specification for Coarse and Fine Aggregates from Natural Sources for Concrete, 2nd ed. New Delhi: Bureau of Indian Standards, 2002.

[23] Indian Standard, Concrete Admixtures-Specification, 1st ed. New Delhi: Bureau of Indian Standards, 2004.

[24] Indian Standard, Concrete Mix Proportioning-Guidelines, 1st ed. New Delhi: Bureau of Indian Standards, 2009.

[25] ASTM C642, Standard Test Methods for Density, Absorption, and Voids in Hardened Concrete, PA: ASTM International, 2013.

[26] ASTM C1202, Standard Test Methods for Electrical Indication of Concretes Ability to Resist Chloride Ion Penetration, PA: ASTM International, 2012.

[27] ASTM C267, Standard Test Methods for Chemical Resistance of Mortars, Grouts, and Monolithic Surfacings and Polymer Concretes, PA: ASTM International, 2012.

[28] G. D. Bella, V. Fiore, G. Galtieri, C. Borsellino, and A. Valenza, "Effects of Natural Fibres Reinforcement in Lime Plasters (Kenaf and Sisal vs. Polypropylene)," Construction and Building Materials, vol. 58, pp. 159-165, May 2014.

Copyright $\odot$ by the authors. Licensee TAETI, Taiwan. This article is an open access article distributed under the terms and conditions of the Creative Commons Attribution (CC BY-NC) license (https://creativecommons.org/licenses/by-nc/4.0/). 